\title{
BIM Interoperability Limitations: Australian and Malaysian Rail Projects
}

\author{
Russell Kenley ${ }^{1, a}$, Toby Harfield ${ }^{2}$ and Ali Behnam ${ }^{3}$ \\ 1, 2, 3Swinburne University of Technology, PO Box 218, Hawthorn, Victoria, 3122, Australia \\ ${ }^{1}$ Unitec Institute of Technology, 139 Carrington Road, Mount Albert, Auckland 1025, New Zealand
}

\begin{abstract}
Building information modelling (BIM) is defined as a process involving the generation and management of digital representation of physical and functional characteristics of a facility. The purpose of interoperability in integrated or "open" BIM is to facilitate the information exchange between different digital systems, models and tools. There has been effort towards data interoperability with development of open source standards and objectoriented models, such as industry foundation classes (IFC) for vertical infrastructure. However, the lack of open data standards for the information exchange for horizontal infrastructure limits the adoption and effectiveness of integrated BIM. The paper outlines two interoperability issues for construction of rail infrastructure. The issues are presented in two case study reports, one from Australia and one from Malaysia. The each case study includes: a description of the project, the application of BIM in the project, a discussion of the promised BIM interoperability solution plus the identification of the unresolved lack of interoperability for horizontal infrastructure project management. The Moreton Bay Rail project in Australia introduces general software interoperability issues. The Light Rail Extension project in Kuala Lumpur outlines an example of the integration problems related to two different location data structures. The paper highlights how the continuing lack of data interoperability limits utilisation of integrated BIM for horizontal infrastructure rail projects.
\end{abstract}

\section{Introduction}

According to The Business Value of BIM for Construction in Major Global Markets, SmartMarket Report [1], an increasing number of construction organisations globally are realizing the advantages of digital construction modelling. The cumulative effort and improvements of computer aided design (CAD) in the construction industry has resulted in increasing adoption of a promising technology, building information modelling (BIM). BIM technology aims to provide a shared knowledge resource for information about a facility throughout its lifecycle [2]. BIM methodology is based on an intelligent, object-oriented, data-rich and parametric digital representation of physical and functional characteristics of a facility.

The adoption of "open" or integrated BIM is important for increasing production and process efficiency in construction projects. The purpose of "open" or integrated BIM is to facilitate more effective exchange of information between different digital systems, models and tools [3]. Consequently, the continuing efforts towards an integrated practice have resulted in the development of open source standards and object-oriented models, such as industry foundation classes (IFC) for vertical infrastructure [4]. However, there is still lack of data standards which could enable the information exchange of rail construction which is an example of horizontal infrastructure. This shortcoming limits the adoption and effectiveness of integrated and "open" BIM for rail projects.

The balance of this paper outlines two interoperability issues for construction of rail infrastructure. The issues are presented in two government procured rail construction case study reports in section 2. Each case study includes: a description of the project, the application of BIM in the project, a discussion of the promised BIM interoperability and identification of the unresolved lack of interoperability for the particular rail infrastructure project. The main sources of our findings included the website of the projects, several journal articles, industry reports and also a university thesis.

The first case study presented is the Moreton Bay Rail project in Australia. This interoperability discussion provides an introduction to incompatibility issues effecting software modelling for general project management. The second case study report is for the extension to the LRT rail system in Kuala Lumpur. It outlines an example of the lack of interoperability because of differences between specific digital data being generated. Different location data structures highlight the problems of information exchange from different digital modelling systems for construction management. The Discussion highlights the importance of open source data standards for improving interoperability. The section also explains about some of the on-going international efforts to facilitate data transfer in these types of projects. The

\footnotetext{
${ }^{\text {a }}$ Corresponding author: rkenley@swin.edu.au
} 
Conclusion summarises the lack of general and specific interoperability in construction models for rail projects that is applicable for all horizontal infrastructure construction.

\section{Australian Case Study: Moreton Bay Rail}

\subsection{Project Description}

The Queensland Transport and Main Roads State Planning Program is based on analysis of current and future integrated passenger transport options. Investment decisions must take into account the challenges of distance in order to deliver quality transport networks for a growing population. Use of the Regional Queensland Passenger Transport Network Plan assists with the identification of appropriate network services for designated regions to provide better and more sustainable transportation options.

The Moreton Bay region of Queensland is the third largest Local Government Area in Australia and is also one of the fastest growing areas in Australia. Population growth is expected to continue over the next 15 years which will cause a significant transportation problem if the use of private cars grows at the same pace as the population. The result of Moreton Bay population growth will be higher values of traffic into Queensland capital city, Brisbane.

The Moreton Bay Rail (MBR) project involves construction of a new $12.6 \mathrm{~km}$ dual heavy track passenger rail line between Lawton and Kippa-Ring that includes six new railway stations and significant road and bridge construction to provide feeder routes to these stations. This new integrated transport passenger rail corridor is located approximately 23 kilometres north of the Brisbane Central Business District [5].

The six new stations: Kallangur, Murrumba Downs, Mango Hill, Mango Hill East, Rothwell and Kippa-Ringg will all provide full passenger services. The services include: $175 \mathrm{~m}$ long side platforms, walkways, ticket offices, waiting facilities, park and ride facilities and bus/train interchanges. All of these facilities and structures are contracted for design and build for the client, Queensland Transport and Main Roads (QTMR).

\subsection{BIM Application}

This type of public transport major works project [6] is expected to be able to take advantage of the opportunity to utilise promising technology such as building information modelling (BIM). The Moreton Bay Rail project design has two distinctive components.

The first component relates to the buildings and architectural elements that use object-based BIM. However, these object-based models do not fit easily into the $12 \mathrm{~d}$ string-based modelling required by QTMR for construction of horizontal infrastructure [5].

The second project component relates to geometric elements including railway embankment alignments, the access roads, bridges, landscaping and the pedestrian walkways. In this domain, string-based modelling solutions, such as $12 \mathrm{~d}$ system, are essential because working with object-based BIM solutions is painstakingly inefficient.

\subsection{Unsolved Modelling Interoperability Issue: String-based and Object-based}

Associated BIM tools have evolved from 2D CAD drawings to 3D models embedded with intelligent objectbased, parametric data. However, as with all new technology, there is a lag between the promised and industry capacity and capability. Currently the construction industry is moving very slowly toward a more integrated practice of BIM processes for better interoperability between different tools for vertical built environment.

However, as the client and eventual owner of the Moreton Bay Rail, all documents for the project need to ultimately be available to QTMR. Their customised BIM system is the $12 \mathrm{~d}$ software solutions which create stringbased models. In addition a significant number of construction design and implementation software tools have been researched and developed specifically for QTMR construction standards and transportation use regulations.

Because all works have standard requirements such road and rail signage or lighting, all contractors are required to use the QTMR software for some parts of a project. This procurement strategy aims to ensure that all construction documentation is compatible with their customised 12d system [5]. Nevertheless, for the Moreton Bay Rail project this has not been possible because of the modelling systems being used by the Architects and Contractors on the project.

An example, integration of models generated from the two different approaches (object-based and string-based) can take place within Navisworks via IFC export or direct export. At the same time this process has proven to be challenging (in terms of time and skills availability). The Moreton Bay Rail project team are effectively using IFC object data in the Navisworks software. However, a major shortcoming of the process is that the digital information exchange is only a one-way process once the models are imported into Navisworks. It would be expected for interoperability information exchange would be a two-way process. The ability to import and export models with ease must be the definition of interoperability.

This case study highlights the interoperability challenge that negatively effects current construction of horizontal infrastructure. Incompatibility of software systems (string-based horizontal infrastructure models and BIM vertical infrastructure object-based models) does not allow the promised information exchange efficiency of digital modelling using a BIM environment. Consequently, effective utilisation of "open" or integrated BIM is limited for this critical construction process for horizontal infrastructure construction management [7]. 


\section{Malaysian Case Study: Kuala Lumpur Light Rail Transit (Extension)}

\subsection{Project Description}

In the past five years under the Tenth Malaysia Plan the Malaysian construction sector has expanded significantly supported by strong activities in civil engineering and linear infrastructure projects particularly railways and roads [8]. One example is the Mass Rapid Transit system in the city of Kuala Lumpur. It is the largest infrastructure in Malaysia which began in 2011 and is expected to be completed in 2020. This $60 \mathrm{~km}$ transportation corridor involves an estimated RM30 billion investment which indicates the commitment to better and more sustainable transportation options.

The Mass Rapid Transit corridor aims to integrate all previous and on-going LRT extension projects. The aim of the Light Rail Transit (LRT) extension projects is to encourage a greater number of public transport passengers. The expectation is to increase the use from 21 $\%$ to $40 \%$ by 2030 under the National Land Public Transport Master Plan target [9]. The LRT extension project is an elevated rail line running through a highly dense urban area. The construction of the guideway consists of 1000 piers through 35.5 kilometres and 25 stations.

\subsection{BIM Application}

The Construction Industry Transformation Program, 2016-2020 [10] outlines the critical importance of enhancing productivity, efficiency and cost effectiveness of the domestic construction industry by leveraging ICT. In particular, the adoption of BIM technology is encouraged by the Malaysia Public Works Department. They have established a special BIM Committee that is in the process of publishing Malaysia BIM Roadmaps, National Standards, Manuals and Guidelines.

Discussion of BIM and the current Kuala Lumpur LRT construction projects provides evidence of the necessity of these aspirational BIM objectives. The construction process for a large rail project is complex and involves excessive amounts of data (drawings and documents) that needs to be exchanged between numerous stakeholders. One of the most important information exchange processes is the critical role of monitoring and reporting construction progress.

The traditional practice for Malaysian rail projects has been to collect and report progress monthly. For LRT projects the monthly progress reports are usually hundreds of pages long including: Gantt charts, work descriptions, site photos and attached specification reports [11]. The variety of types of documents and information formats make the monthly progress reports difficult to store, read and analyse. Thus, progress reporting is a time consuming process for both data collection and progress report preparation.

This important project process presents an opportunity to achieve the government's BIM objective of more effective and efficient data transfer. The complexity of large infrastructure projects means, of course, complex progress reports. Thus, a more efficient process was considered an excellent trial for digital information exchange technologies by integrating geographic information systems (GIS) and digital construction models for progress reporting of the LRT extension construction project. Researchers have examined the adoption of GIS and 2D/3D models to collect, store, analyse, visualise and exchange information related to construction progress [12]. GIS provides $2 \mathrm{D}$ data in very large scale. The argument is that the digital data integration of CAD/BIM data with 2D GIS could allow more sophisticated analysis of large datasets for location information exchange.

For the elevated LRT extension project in Kuala Lumpur, a progress monitoring framework was developed based on both the planned and actual progress data for each location in the project. The location data is collected, reported and visualized in a digital CAD/GIS platform [13]. While this method of providing construction progress should have been more effective, the LRT CAD model and the satellite image of the construction site do not use the same location structures. Thus, data integration, or interoperability remains a problem.

\subsection{Unsolved Interoperability Issue: CAD \& GIS Location Identifiers}

The LRT CAD model represents the construction project design, including the relative coordinates, shape, size and orientation of every construction component and unit. The coordinate system used in CAD drawing is defined with local location identifiers such as streets names or government boundaries. GIS uses a completely different system. Location identifiers are based on a global geographical reference system.

Therefore, interoperability of information exchange of specific location data remains an issue. The location identifiers have different data structures with completely different scales of measurement. Integrating these two models of location is a challenging task because it requires manual translation between two data sources. Therefore, digital data collection and preparation of construction progress report does not provide adequate reduction of time and effort. Consequently, effective utilisation of "open" or integrated BIM is also limited for this critical construction process for horizontal infrastructure construction management [7].

\section{Discussions}

Governments need to provide transportation services to ensure economic and social activity, and to provide these services in a cost-effective manner. However, the lag between promised efficiency from adoption of BIM and industry BIM capability and capacity makes it difficult for government decision-makers. Both Australia and Malaysia have attempted to take advantage of technological advances afforded by the emerging BIM 
systems, models and tools, but global construction industry practice is slow to change.

The lack of current standards for horizontal infrastructure is a major obstacle for effective data exchange in these types of projects. Therefore, an Open Source definition for BIM is necessary as the solution to enabling interoperability and hence promoting an integrated practice. BuildingSMART as an international organisation facilitates the development of open standards such as IFC for building industry and vertical infrastructure [14].

The buildingSMART has recently commenced the IFC for infrastructure project to expand the IFC to support horizontal infrastructure projects [15]. The first IFC for infrastructure is the IFC alignment which is collaboration between buildingSMART and open geospatial consortium (OGC). The aim of this project is to provide standards for exchange of alignment information (including 2D, 3D vertical and horizontal) throughout the infrastructure lifecycle. These standards extend IFC to include OGC standards that support global rather than local geographic coordinates and levels. By using the expected standards, the geometric data can be accurately exchanged through different systems, models and tools with minimum data redundancy.

Furthermore, the buildingSMART is also attempting to develop data models for road, rail, and bridge and tunnels to fulfil these project data needs such as element breakdown, detailed material information, earthwork (digital terrain model, fill and cut, geological volumes) and other information.

\section{Conclusions}

Development of "open BIM" to facilitate integrated construction management does seem to have made some headway in construction of vertical infrastructure. However, interoperability issues specific to horizontal infrastructure are yet to be solved.

This paper provides two case studies discussing adoption of digital information exchange technology for rail construction. The Australian project focused on the two way exchange of object-based and string-based design. The Malaysian project focused on the integration of a CAD construction model and GIS digital data collection. Both case studies outline interoperability problems related to modelling issues for horizontal infrastructure which are indicative of the difficulties of the aspiration for "open" or integrated BIM.

These studies identify only two examples of BIM interoperability issues. One is a general problem of information exchange between string-based and objectbased design. The other examines the specific problem of different location data structures. Clearly, to maximize the effectiveness of BIM as an integrated practice for horizontal infrastructure, it is important to increase interoperability between different systems, models and tools.

The continuing international efforts for development of open data standards and object-based models, such as the Industry Foundation Classes (IFC) are supportive of open BIM for vertical infrastructure. However, the lack of emphasis on the standardization of data needs and requirements of horizontal infrastructure remains a problem for governments in their quest for effective digital systems for rail construction. This limitation should encourage future researchers to investigate the needs of information exchange in these projects. The ongoing standardisation projects such as IFC alignment could enhance the interoperability and integration of different object-based, alignment-based and GIS models.

\section{Acknowledgement}

The Swinburne University of Technology MelbourneSarawak Research Collaboration Scheme ID number 3000004617 has funding for this research.

\section{References}

1. McGraw Hill Construction The Business Value of BIM for Construction in Major Global Markets, SmartMarket Report (2014) Online: https://synchroltd.com/newsletters/Business $\% 20$ Valu e\%20Of\%20BIM\%20In\%20Global\%20Markets\%20 2014.pdf

2. C. Eastman, P. Teicholz, R. Sacks, \& K. Liston, BIM handbook: A guide to building information modeling for owners, managers, designers, engineers and contractors. ( $2^{\text {nd }}$ ed.) Hoboken, NJ: Wiley (2011)

3. M. Laakso \& A. Kiviniemi "The IFC standard - a review of history, development, and standardization.” J. Info. Tech., 17, 134-161 (2012) Online: http://www.itcon.org/2012/9

4. J. Steel, R. Drogemuller \& B. Toth, "Model interoperability in Building Information Modelling." Software and Systems Modelling, 11, 99-109 (2012)

5. (QTMR) Queensland Transport and Main Roads (2015) Transport-and-Main-Roads-12D-modelcustomisation Online: http://www.tmr.qld.gov.au/business-industry/Roadsystems-and-engineering/Software/Transport-andMain-Roads-12D-model-customisation.aspx

6. N. Lee, T. Salama, \& G. Wang, "Building information modeling for quality management in infrastructure construction projects." In Issa, R., \& Flood, I. (eds.) Proc. Comput. in Civ. and Build. Eng., 65-72 (2014) Online: http://ascelibrary.org/doi/abs/10.1061/978078441361 6.009

7. M. Laakso \& A. Kiviniemi. "The IFC standard - a review of history, development, and standardization.” J. Info. Tech., 17, 134-161 (2012) Online: http://www.itcon.org/2012/9

8. CIDB, Construction Industry Review. Kuala Lumpur, Malaysia: Construction Industry 
Development Board Malaysia (2009)

9. Prasarana Malaysia Berhad, LRT Line Extension, About the Project (2015) Online: http://www.myrapid.com.my/projects/lrtextension/ab out-project/about-project

10. CIDB.. The Construction Industry Transformation Program, 2016-2020. Kuala Lumpur, Malaysia: Construction (2015) Industry Development Board Malaysia. Online: http// www.citp.my/download.php? $\mathrm{f}=\mathrm{CITP}$-public.pdf

11. Sunway Group Construction , Monthly Progress Reports. Kuala Lumpur: Prasarana Malaysia Berhad (2012)

12. S. El-Omari \& O. Moselhi, (2011). "Integrating automated data acquisition technologies for progress reporting of construction projects" J. Automati. in Constr., 20, 699-705.

13. A. Behnam, A Study on the Application of LocationBased Management and Automated Progress Monitoring for Linear Construction Projects, Unpublished MPhil thesis. Semenyih: University of Nottingham Malaysia Campus (2015)

14. R. Kenley \& T. Harfield, New Project Management Models: Productivity Improvement for Infrastructure. Perth: SBENRC (2014)

15. BuildingSMART, IFC Infrastructure Room, (2015) Online: http://www.buildingsmarttech.org/infrastructure 